\title{
Special needs of in-school HIV positive young people in Uganda
}

\author{
Francis Obare \\ Harriet Birungi \\ Population Council \\ Anne Katahoire \\ Hannington Nkayivu \\ Aggrey David Kibenge
}

Follow this and additional works at: https://knowledgecommons.popcouncil.org/departments_sbsr-rh

Part of the Demography, Population, and Ecology Commons, Family, Life Course, and Society

Commons, Gender and Sexuality Commons, International Public Health Commons, Medicine and Health

Commons, and the Women's Health Commons

How does access to this work benefit you? Let us know!

\section{Recommended Citation}

Obare, Francis, Harriet Birungi, Anne Katahoire, Hannington Nkayivu, and Aggrey David Kibenge. 2009.

"Special needs of in-school HIV positive young people in Uganda." Nairobi: Population Council. 
Special needs of in-school HIV positive young people in Uganda 31 (1) 6 1 6 - $120 \%$ s) (2) 620 (6)

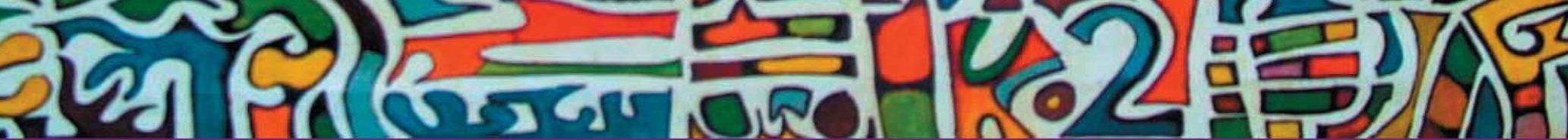




\section{Special needs of in-school HIV positive young people in Uganda}

Francis Obare ${ }^{1}$, Harriet Birungi ${ }^{1}$, Anne Katahoire ${ }^{2}$,

Hannington Nkayivu ${ }^{3}$, Aggrey David Kibenge ${ }^{4}$

June 2009

1Population Council,

${ }^{2}$ Child Health and Development Center, Makerere University,

${ }^{3}$ TASO - Uganda,

${ }^{4}$ Ministry of Education-Uganda 


\section{(2) Population Council}

The Population Council conducts research worldwide to improve policies, programs, and products in three areas: HIV and AIDS; poverty, gender, and youth; and reproductive health.

(C) 2009 The Population Council, Inc.

Any part of this publication may be reproduced without permission for limited distribution provided it is distributed without charge and the Population Council is acknowledged as its source. The Population Council would appreciate receiving a copy of any materials in which the text is used.

Cover painting: (C) 2009, Eirik Jarl Trondsen

Eirik Jarl Trondsen born in Oslo, Norway, studied in Uganda, and worked with art in the Kibera slum of Nairobi and currently lives in Kenya. Contact: ejtconsult@gmail.com. The painting on the cover page of this report signifies the colourful and energetic world. It represents a transition between form and formless inspires, and includes shapes and words of life: integrity, responsibility, hope and justice for all. It is inspired by the need we all have to be true to ourselves, as well as those we meet on our way.

Suggested citation: Francis Obare, Harriet Birungi, Anne Katahoire, Hannington Nkayivu and Aggrey David Kibenge. 2009. Special needs of in-school HIV positive young people in Uganda. Reproductive Health Program, Population Council. 


\section{ACKNOWLEDGEMENTS}

This study was made possible through financial support from the Ford Foundation. It was implemented by the Population Council in collaboration with the Child Health and Development Centre - Makerere University, The AIDS Support Organization (TASO) - Uganda, and the HIV/AIDS Unit in the Ministry of Education- Uganda.

We acknowledge contribution from Florence Baingana (Institute of Public Health, Makerere University), who carried out the school environment assessment in four schools; Sande Kabirizi (Ministry of Education), who mobilized the schools and participated in the school environment assessment; Christabel Hoka managed qualitative data from students essays; and Nkeonyere Ezeh, a Private Consultant who entered, analyzed and prepared a short report on HIV in schools based on data from the students' essays.

Invaluable support was received from the Head Teachers and Staff of Victoria Nile School in Jinja, Namugongo Girls School, Mengo Secondary School, Kajansi Progressive Secondary School, Wanyange Girls Secondary School, and Busoga College Mwiri. We would like to thank Dr. Robert Ochai, the Executive Director of TASO, Mrs. Juliana Nyombi, Director, Capacity Development and Training- TASO, and the managers and staff of TASO branches in Kampala, Entebbe, Jinja and Masaka as well as other HIV/AIDS treatment, care and support centers that granted the research team access to the children who receive services from the centers. These include TASO Mulago, TASO Kanyanya, and Kawempe Health Center in Kampala; TASO Jinja, Mutai Health Centre, Buwenge Health Centre, and Nalufenya in Jinja; TASO Masaka, Kitovu Mobile, Uganda Cares, and Villa Maria Home Care in Masaka; and TASO Entebbe.

We are grateful to our informants to the success of the study, that is, the school officials, students, and young people living with HIV and their parents/guardians. The successful completion of the study was also made possible by the dedicated team of researchers, including Florence Tagoola (study coordinator), Victor Guma, Lynda Nakalawa, Godlove Nantumbwe, Joy Guminkiriza, Priscilla, Tezie Nakayima, Mariam Nankabirwa, and Hannah Nyombi (research assistants), Jonathan Ngobi (translator), as well as Vincent Iga and Ali Mukungu (data entry).

Philisters Obunga of the Population Council provided invaluable administrative support for the study.

The research team obtained ethical clearance for the study from TASO Internal Review Board, the Uganda National Council of Science and Technology (UNCST), and the Population Council's Institutional Review Board. 


\section{CONTENTS}

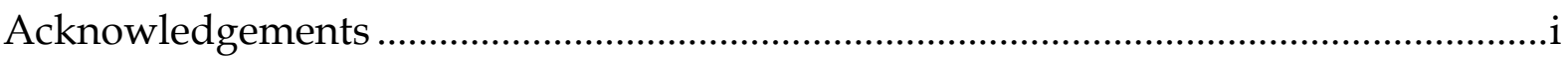

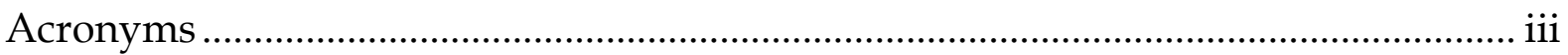

Executive summary ......................................................................................... iv

Key findings................................................................................................. iv

Programmatic implications .............................................................................. vi

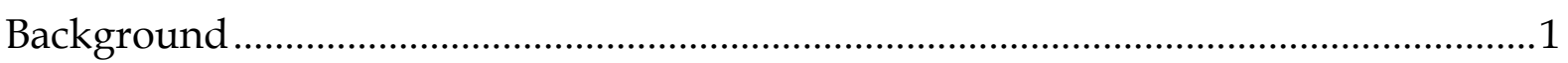

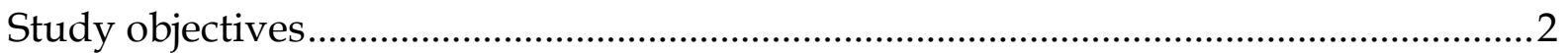

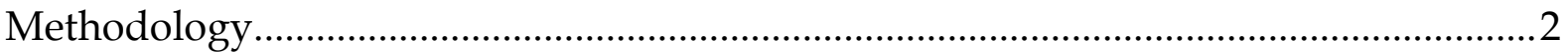

School environment and preparedness ………………..............................................

Attitudes and practices of students and teachers..........................................................6

School attendance and educational attainment..........................................................10

Motivations for schooling .........................................................................................12

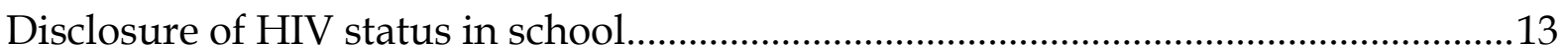

Experiences of abuse, stigma and discrimination .......................................................16

Psychosocial problems and schooling …………………......................................17

Support groups and services in schools ..................................................................2 20

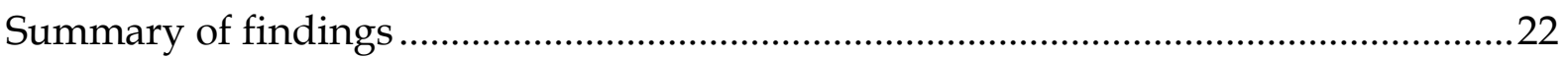

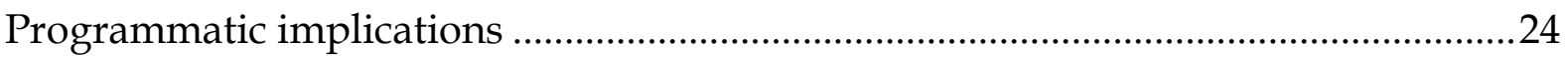

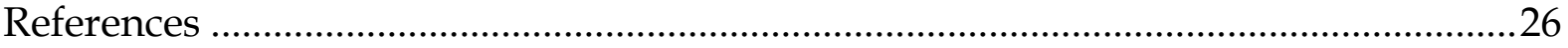




\section{ACRONYMS}

AIDS Acquired Immunodeficiency Syndrome

ART Antiretroviral Therapy

HIV Human Immunodeficiency Syndrome

PIASCY Presidential Initiative on AIDS Strategy for Communication to Youth

SRH Sexual and Reproductive Health

TASO The AIDS Support Organization

UNCST Uganda National Council of Science and Technology

UNESCO United Nations Educational, Scientific and Cultural Organization

UNICEF United Nations Children's Fund

USAID United States Agency for International Development

VCT Voluntary Counseling and Testing 


\section{EXECUTIVE SUMMARY}

Since 2006, Population Council, with funding from the Ford Foundation and USAID, has pioneered operations research in collaboration with local partners in Uganda to promote the sexual and reproductive health (SRH) rights of young people, aged 1019 years, infected with HIV. Key findings from this project show that many young people perinatally infected with HIV desire to be in school to avoid social isolation and indeed about 70 percent of them attend school. However, there has been limited understanding of how the education sector should support this vulnerable group of learners.

The objective of this study was to explore the special needs HIV positive young people in primary and secondary schools in Uganda with a view to identifying possible responses by the education sector to these needs. It was implemented by the Population Council in collaboration with the Child Health and Development CentreMakerere University, The AIDS Support Organization (TASO)- Uganda, and the Ministry of Education- Uganda, through funding from the Ford Foundation. It involved a survey of 718 young people aged 12-19 years perinatally infected with HIV, in-depth interviews with 52 school officials, and 938 student essays on identified HIV/ AIDS themes.

\section{Key findings}

Lack of adequate material support for schooling: Both school officials and the adolescents perinatally infected with HIV recognized lack of adequate material support (fees and learning materials) for adolescents living with HIV in schools. This is largely occasioned by the fact that most of the adolescents are orphans having lost one or both parents. In-depth interviews with school officials reveal that support from guardians is not always adequate as some of them believe that the children might not live long or simply because of poverty. It is one of the main reasons for missing school or repeating classes, as well as for experiencing psychosocial problems which, in turn, affect school attendance and performance.

Lack of proper mechanisms for health care in schools: Illness and having to seek treatment from elsewhere are major factors in missing or not currently attending school among adolescents perinatally infected with HIV. They are also some of the most commonly cited reasons for experiencing psychosocial problems. In-depth interviews with school officials further show that HIV positive young people in boarding institutions face additional challenges such as poor diet, adherence to ART, and taking cold showers. These have implications for academic performance. However, schools lack formally established mechanisms for meeting these needs. Moreover, sick-bays-- where they exist in schools-- are ill-equipped while the school nurses are inadequately trained to handle the health needs of HIV positive young people. 
Lack of training in HIV care and support for caregivers: In-depth interviews with school officials showed that most of those who provide some kind of support at school to HIV positive adolescents lack appropriate training in HIV care and support. These include the school nurses, guidance and counseling teachers, and senior teachers. Adolescents perinatally infected with HIV who received some kind of support from schools reported receiving the same from head teachers as well, who might also not have adequate training in HIV care and support.

Non-disclosure of HIV status in school: More than half of the adolescents had not disclosed their HIV status to teachers and four-in-five had not disclosed to the school nurse. In-depth interviews with school officials reveal that non-disclosure of HIV status is a major impediment to providing appropriate and timely support to inschool HIV positive adolescents. The fear of stigma or discrimination, losing friends, being ridiculed, or of those disclosed to telling others were some of the major reasons for non-disclosure of HIV status at school. In-depth interviews with school officials further showed that parents/guardians feared that their children might not be admitted in school if they disclosed their (children's) HIV status. It is, however, worth noting that those who had disclosed their sero-status to others mostly reported being shown compassion/sympathy, counseled, or being helped with medication, which suggests that some of the fears about disclosure might be unfounded.

Lack of support groups/clubs or services in school: Only a small fraction of the adolescents reported having support groups/clubs for HIV positive young people in their learning institutions or receiving any kind of support from school. Whereas it can be argued that the existence of support groups/clubs or services in schools specifically for HIV positive young people can reinforce stigma and discrimination, the findings of this study show the contrary. Rather, nearly all those who received some kind of support from the groups/clubs or schools-- where these exist-- were satisfied with it. Furthermore, the majority of those currently attending school supported the need for having such groups/clubs in schools. The establishment of such groups/clubs was also one of the ways in which the school administration could support in-school HIV positive young people that the students identified in the essays.

Discrimination, stigma and physical abuse in schools: The fact that the existence of support groups/clubs or services for in-school HIV positive young people does not reinforce stigma or discrimination does not imply that these problems do not exist. In fact, nearly one-in-five of the perinatally infected adolescents currently attending school reported being teased or called nasty names at school because of their HIV status, and one-four suspected rumors spreading in school about their sero-status. In addition, in-depth interviews with school officials and student essays show that stigma and discrimination of in-school HIV positive young people-- either by others or self-imposed-- is still a problem. 


\section{Programmatic implications}

School-based programs to assist orphans and other vulnerable children: The study shows that orphans and other vulnerable children, including those living with HIV lack the relevant learning materials and other basic needs (such as lack of proper diet) that affect school attendance, and which could affect their academic performance as well. The Ministry of Education and Sports, in collaboration with other relevant ministries, therefore needs to come up with a school-based program that caters for the special needs of not only these children but also all orphans and other vulnerable children so that they do not miss attending school for lack of essentials.

Strengthen the school-based health care program: The Ministry of Education and Sports needs to collaborate with the Ministry of Health to strengthen the schoolbased health care program. The program should include treatment, care and support for HIV positive pupils/students, encouraging in-school young people to undergo testing and counseling for HIV, and equipping the sick bays-- where these exist-with essential medicines such as antibiotics and anti-malarial drugs. A common theme from the in-depth interviews with school officials and the student essays is to enhance the capacity of schools to either provide these services or have in place proper mechanisms for referring pupils/students in need of the services to the relevant facilities. Having counselors from the treatment centers visit schools to provide guidance and counseling is another way of strengthening the health care program in schools that was identified by school officials and students alike. The other strategy for strengthening the health care program in schools is to replicate the youth-friendly health services all over the country so as increase the chances of appropriate referral to these facilities by the schools.

Offer caregivers at school training in HIV care and support: The fact that school nurses and teachers who provide some kind of support to in-school HIV positive young people lack the relevant training suggests the need for the Ministry of Education and Sports to offer pre- or in-service training-- as appropriate-- in counseling, care and support to these caregivers. For pre-service training, these themes need to be incorporated in the curriculum. In-service training needs to focus on enhancing the capacity of school nurses, teachers, matrons and all those that directly interact with pupils/students to effectively manage and support those in need of HIV and AIDS-related services as a strategy for strengthening the health care program in schools as well.

Encourage the formation of support groups or clubs for HIV positive young people in schools: The study finds that nearly all respondents with support groups/clubs for HIV positive young people in their schools and are members are satisfied with the kind of support they receive although only a very small fraction reported having such groups/clubs in their learning institutions. The Ministry of Education and Sports therefore needs to come up with a policy encouraging schools to have such groups/clubs. The fact that most of those who are members are satisfied with the support they receive suggests that the groups/clubs could be a way of fighting 
rather than reinforcing stigma and discrimination. The clubs could be expanded to incorporate all pupils/students irrespective of their HIV status but with the objective of supporting those who are HIV positive as well as fighting stigma and discrimination through the use of innovative ways such as child-to-child education and communication.

Measures to discourage stigma and discrimination: The need for measures that discourage stigma and discrimination of in-school HIV positive students was a recurring theme in the in-depth interviews with school officials and the student essays. This can be achieved, for instance, through programs aimed at sensitizing school officials and students on the consequences of discrimination and stigmatization on those who are exposed to them. The Ministry of Education and Sports therefore needs to collaborate with school officials to formulate a policy that outlines measures aimed at discouraging stigma and discrimination of in-school HIV positive young people. Such measures include programs aimed at educating school officials and teachers about HIV/AIDS, as well as advocacy to have school management allocate resources for anti-AIDS campaigns within the school budget. This could, in turn, increase the propensity to disclose one's sero-status, and ensure appropriate and timely response to the needs of HIV positive students by the school officials. In addition, having HIV/ AIDS counselors in schools could help reduce selfimposed stigma. 



\section{BACKGROUND}

Since 2006, Population Council, with funding from the Ford Foundation and USAID, has pioneered operations research in collaboration with local partners in Uganda to promote the sexual and reproductive health (SRH) rights of young people, aged 1019 years, infected with HIV. This initiative seeks to improve the sexual well-being of these young people by integrating a broad perspective of reproductive health and sexuality information and services into existing HIV/AIDS treatment, care and support programs. Key findings from this project show that many young people perinatally infected with HIV desire to be in school to avoid social isolation and indeed about 70 percent of them attend school. However, UNICEF has, for instance noted that educational performance of children started on ART at an early age and who survive long enough to enter the schooling system is relatively poor due to absenteeism.

African governments are beginning to recognize the school-going HIV positive pupils as presenting a new challenge to the education sector (Kelly 2003). In response, many governments have moved to develop Education Sector Policies on HIV/ AIDS, whose scope of application includes all pupils, employees, managers and administrators in all public and private, formal and non-formal learning institutions at all levels of the education system (Ministry of Education and Sports 2004). The policies have predominantly evolved around a legal framework that recognizes and upholds the rights of all people with a special focus on marginalized and vulnerable groups and those with special needs. The policies also recognize the need for universal access to HIV/AIDS information, access to treatment and care, protection from discrimination and stigma, and care for orphans and vulnerable inschool young people.

Although existing policies recognize school-going HIV positive young people as a vulnerable population, education sector policy responses to HIV/AIDS are predominantly curriculum-based, focusing almost entirely on developing the capacity of learners in three areas: better knowledge about the diseases, skills that enhance the ability to protect oneself against infection, and approaches that acknowledge the rights and dignities of those infected and affected. Insufficient attention is paid to the special needs of pupils living with HIV, a problem compounded by the fact that their special needs are largely unknown perhaps because very few HIV positive pupils have disclosed their sero status. For instance, the Population Council study in Uganda showed that only 14 percent of schoolgoing young people living with HIV had disclosed their HIV status to their teachers. Worse still, systematic studies that inform programming for the special needs of school-going HIV positive young people are virtually non-existent. Consequently, school- based programs for this small but rapidly growing population of learners are absent.

Moreover, the United Nations Educational, Scientific and Cultural Organization (UNESCO) has warned that with increased access to treatment across East and Southern Africa, the need to support in-school HIV positive pupils will only gain 
urgency and scale. In spite of this, there has been limited understanding of how the education sector should support this vulnerable group of learners. To respond to this concern, Population Council conducted an exploratory study in Uganda to better understand the special needs of HIV positive young people in primary and secondary school settings.

\section{STUDY OBJECTIVES}

- To explore what special needs HIV positive young people in primary and secondary schools in Uganda have; and

- To identify possible responses by the education sector to these needs.

\section{Methodology}

The study involved two major components. The first component was a survey among 718 young people aged 12-19 years (i.e. of school-going age) who were perinatally infected with HIV and who knew their sero status. The sample members were identified and recruited through existing HIV/AIDS treatment, care and support programs/centers selected by The AIDS Support Organization (TASO)Uganda in four districts (Kampala, Wakiso, Masaka and Jinja). Thirteen such centers participated in the study. TASO counselors assisted with the identification and mobilization of the respondents. The process involved obtaining clearance from the management of the centers, identifying the target sample from the existing records, and making calls to their parents to request them to come to the centers or targeting days when they visit the centers for routine reviews or drug re-fills.

The TASO Internal Review Board, the Uganda National Council of Science and Technology (UNCST), and the Population Council's Institutional Review Board granted ethical clearance for the study. For non-emancipated adolescents aged 12-17 years, written consent to participate in the study was sought from parents/guardians and the adolescents themselves. However, the study did not seek parental/guardian consent for adolescents aged 18-19 years and emancipated minors aged $12-17$ years.

Information was collected using a structured questionnaire which was translated into Luganda and Lusoga, the two dominant local languages. Interviews were partially completed with 6 of the participants. Information was gathered on the respondents' background characteristics, educational attainment, school attendance (absenteeism, repetition, changing of schools, and drop-out), motivations for being in school or dropping out, disclosure of HIV status within the school environment and the reactions of others to the disclosure, availability of support programs for HIV positive young people within schools, psychosocial feelings in school and whether these affected school attendance, and experiences of physical or verbal abuse, discrimination and stigma in school. 
Female respondents comprised more than half (59\%) of the survey participants, although there was no significant difference in the distribution by sex in most of the background characteristics such as age, district of residence, whether the respondent lived with a biological parent, and the living arrangements of the biological parents (Table 1). Nearly two-thirds (65\%) of the respondents were aged below 18 years, hence considered minors while slightly more than one-third (36\%) were from Kampala district. Four-in-five $(80 \%)$ of the respondents reported that one or both parents had died, which suggests that the majority of them might lack proper support not only in school but also at home.

Table 1: Distribution of survey participants by various background characteristics

\begin{tabular}{|c|c|c|c|}
\hline & $\begin{array}{r}\text { Male } \\
(\mathrm{N}=294) \\
\%\end{array}$ & $\begin{array}{r}\text { Female } \\
(\mathrm{N}=424) \\
\%\end{array}$ & $\begin{array}{r}\text { Both sexes } \\
(\mathrm{N}=718) \\
\%\end{array}$ \\
\hline \multicolumn{4}{|l|}{ Age group } \\
\hline $12-14$ & 31 & $38^{\text {ns }}$ & 35 \\
\hline $15-17$ & 31 & $28^{\text {ns }}$ & 29 \\
\hline 18-19 & 37 & $33^{\text {ns }}$ & 35 \\
\hline Don't know & 1 & 0 & 0 \\
\hline \multicolumn{4}{|l|}{ District } \\
\hline Jinja & 21 & 28 & 25 \\
\hline Kampala & 40 & $34^{\text {ns }}$ & 36 \\
\hline Wakiso & 7 & $5^{\text {ns }}$ & 6 \\
\hline Masaka & 32 & $33^{\text {ns }}$ & 33 \\
\hline \multicolumn{4}{|l|}{ Lives with a biological parent } \\
\hline Yes & 40 & $39^{\text {ns }}$ & 40 \\
\hline No & 59 & $58^{\text {ns }}$ & 58 \\
\hline Missing/no answer & 1 & $3^{\text {ns }}$ & 2 \\
\hline \multicolumn{4}{|l|}{ Parents' living arrangements } \\
\hline Married/living together & 11 & $11^{\mathrm{ns}}$ & 11 \\
\hline Divorced/separated & 4 & $7^{\text {ns }}$ & 5 \\
\hline Mother dead & 16 & $11^{\mathrm{ns}}$ & 13 \\
\hline Father dead & 27 & $24^{\mathrm{ns}}$ & 25 \\
\hline Both parents dead & 39 & $44^{\mathrm{ns}}$ & 42 \\
\hline Don't know/missing & 2 & $3^{\text {ns }}$ & 3 \\
\hline
\end{tabular}

The second component of the study involved an in-depth assessment of the school environment and their preparedness to support in-school HIV positive young people. A total of eight schools (four primary and four secondary) in five districts (Kampala, Jinja, Wakiso, Mukono and Iganga) were included in the assessment. Two of the primary and two of the secondary schools were mixed day while one school in each category was a boys' only and the other a girls' only boarding institution. The schools were purposively selected in consultation with the Ministry of Education and Sports. The Ministry granted the research team permission to visit the schools and talk to the officials. The research team obtained oral consent for participation in the study from the school officials.

Information was collected through in-depth interviews to determine the existence and operationalization of HIV/AIDS policies in schools, perceptions and practices of teachers and school management towards in-school HIV positive young people, the 
existence of support programs, and possible responses by the education sector to the needs of infected pupils/students. A total of 52 in-depth interviews were conducted with head teachers (7), deputy teachers (4), director of studies (1), deans of students (2), senior teachers (12), Presidential Initiative on AIDS Strategy for Communication to Youth (PIASCY) teachers (3), school nurses/clinical officers (8), school matron (1), peer counselor (1), health prefects (8), and club patrons and members (5) from the selected schools.

In addition, a total 1, 012 students in Senior Three and Five from the four secondary schools wrote essays on specified themes. These included the perceived and actual attitudes and practices of students towards colleagues who are HIV positive as well as possible responses by fellow students and the school administration to the needs of HIV positive students. The essays were anonymous-- students were asked to indicate only their age, sex, and class but not their names-and were administered to

\begin{tabular}{|l|r|r|r|r|}
\hline \multicolumn{6}{|c|}{ Table 2: Distribution of participants in the essays by various } \\
background characteristics
\end{tabular}
the students as a class exercise. It was explained to them that the exercise was voluntary and that they had the freedom not to participate in it if they did not wish to. Twenty nine (3\%) of these essays were, however, discarded because it was apparent the students did not understand the nature of information required. Participants in the remaining essays were aged between 11 and 25 years (Table 2) with $71 \%$ of them being females while $1 \%$ of the students did not indicate their sex.

Data entry and analysis of information collected from the survey were done using EPIDATA and STATA computer packages respectively. The in-depth interviews were tape-recorded, transcribed, typed in Word, and analyzed for content. The essays were analyzed in two ways: qualitative (for content) and quantitative. For the quantitative analysis, each essay was first assigned a unique identifying number, then in Excel, a code ' 1 ' was assigned to an essay for each particular theme that appeared and ' 0 ' otherwise, and the resulting data analyzed using STATA program. The results, together with those from the survey, are presented in the form of frequencies and percentages. 


\section{SCHOOL ENVIRONMENT AND PREPAREDNESS}

The in-depth interviews reveal that while there were HIV positive young people enrolled in all eight schools, none of the schools had any school-based policies, rules or regulations relating to HIV/ AIDS. Although informants from two of the schools indicated that they were following the guidelines stipulated in the Education Sector HIV / AIDS Policy, it was evident that the policy was not operationalized at the school level. Parents and guardians are required by schools to fill out medical forms for pupils/students on admission. This information is used by the schools to identify those with chronic illnesses and other special needs and who might need special attention. However, none of the medical forms completed by parents and guardians indicated HIV/AIDS as one of the chronic illnesses. This could be attributed to the fact that parents and guardians sometimes conceal some ailments, perhaps, for fear that their children may not be admitted if their conditions are known or to protect them from discrimination and stigmatization. This was one of the reasons cited by the school authorities for not having special provisions for HIV positive pupils/students.

With respect to perceptions and practices towards HIV positive pupils/students, informants from all the eight schools acknowledged the right to education of children living with HIV. Although the presence of such children in the schools was not openly discussed, the school authorities reported that once they found out that a particular pupil/student had HIV or other chronic illness, they exempted them from engaging in heavy extra-curricular activities, provided them with special meals where possible, and reminded them to take medicine in cases where the staff members were aware that the children were on ART. Informants reported that pupils/students with full-blown AIDS faced greater challenges including being sickly, missing school often, being isolated and withdrawn, and being shunned and stigmatized by other students. In contrast, those who were HIV positive but asymptomatic were in most cases perceived as not having special needs.

Pupils/students who are orphans lacked proper support and care including learning materials while those in boarding institutions faced additional challenges such as poor diet, adherence to ART, and taking cold showers. As one teacher explained:

"Sometimes their guardians do not genuinely have the money but others are just negligent they feel that 'after all the child may not have long to live'. In cases where the child knows that they are HIV positive this adds to their psychological stress. At school we ask them 'where are the materials we sent you for'; at home they are being told 'we do not have money'. When we do not know their special circumstances we think they are just being stubborn and not informing their parents. But when we find out, we try as a school to see how best to help them. Some teachers even buy them the materials using their own money but this is after they have found out the circumstances." (Senior Woman Teacher/Primary School)

None of the schools included in this study had programs, health services or clubs specifically designed to address the special needs of HIV positive pupils/students. There were, however, various non-formalized attempts to handle HIV positive 
pupils/students in the best way possible with limited resources. These responses were, however, ad hoc, at individual level, and crisis-driven, partly because of nondisclosure by parents/guardians, and partly because of lack of formally established mechanisms for responding to the special needs of HIV positive pupils/students. For instance, school authorities often discovered when the pupil/student became symptomatic while at school or because of continued absenteeism or seeking permission to go for treatment on specific days. Besides, formal access to treatment, counseling, care and support at school or through school was almost non-existent. Some of the schools did not have full-time nurses and the available staff were equipped to provide First Aid treatment only while boarding schools with sickbays commonly stocked antibiotics. The support provided by the schools was mainly informal and a lot seemed to depend on the goodwill of particular head teachers, other teachers, and school nurses who sometimes use their own resources. ${ }^{1}$ Senior men and women teachers, many without training in HIV care and support, provided counseling either in groups or upon request by individual pupils/students.

Informants suggested a number of ways in which the Ministry of Education and Sports, in collaboration with schools and the Ministry of Health, can support inschool HIV positive young people. These include: 1) initiating a school-based program to provide learning materials and other basic needs to orphans, including the provision of food supplements, mosquito nets, malaria drugs, and antibiotics for HIV positive pupils/students, especially those in boarding schools; 2 ) the need to provide training in counseling, care and support for all teachers and nurses in primary and secondary schools; 3) collaborating with schools to introduce measures that discourage discrimination, verbal or physical abuse of those who are HIV positive; 4) collaborating with the Ministry of Health to provide information on how to access ART for pupils/students, have counselors from the treatment centers visit schools, and provide an integrated school health program that covers all chronic illnesses including HIV/AIDS; and 5) formulating a policy that requires all young people in school to undergo VCT, which can be provided in schools as part of an integrated school health program.

\section{ATTITUDES AND PRACTICES OF STUDENTS AND TEACHERS}

One of the themes of the essays was a hypothetical question on how the students would react if they found out that a fellow student was HIV-positive. The most commonly cited reactions were showing love, compassion, friendship or kindness (63\%), encouraging, advising, giving hope, or providing some form of peer counseling to enable the infected student to live positively $(47 \%)$, and showing pity, sympathy, or feeling bad, sad, or sorry about it (41\%; Table 3). A significantly higher proportion of female than male students reported that they would show love, kindness, compassion, support, and associate with the infected compared to their

\footnotetext{
${ }^{1}$ In one school, for example, a teacher reportedly helped HIV positive students to pick their monthly refill of ARVs so that they didn't miss lessons. In another, the head teacher invited the guardian of one of the students to the school, counseled them, and connected them to a treatment centre.
} 
male counterparts $(68 \%$ vs. $52 \%$; p $<0.01)$. Similarly, a significantly higher proportion of female than male students reported that they advise or encourage HIV positive students to live positively ( $49 \%$ vs. $42 \%$; $p<0.05$ ). Nonetheless, both boys and girls were equally likely to mention that they would show pity, feel sad, bad or sorry for an infected schoolmate ( $44 \%$ vs. $40 \% ; \mathrm{p}=0.29)$.

Only a small fraction of the students reported such negative responses like discriminating or isolating a fellow student who is HIV positive $(2 \%)$, telling others or gossiping about it (1\%), and blaming the student for being infected with HIV $(1 \%)$. In addition, an overwhelming majority of the students $(90 \%)$ reported that HIV positive children should be allowed to attend school with no significant difference between male and female students ( $88 \%$ vs. $91 \%$; $p=0.60)$. The most commonly cited reasons in support of school attendance by HIV positive children were that it was their right and that denying them the chance would be an injustice and discrimination (54\%), that it would improve their career and life prospects $(48 \%)$, and that they can contribute positively to society $(40 \%)$.

Table 3: Distribution of most commonly cited possible reactions by students to the presence of a fellow student living with HIV

\begin{tabular}{|c|c|c|c|c|}
\hline Reactions & $\begin{array}{l}\text { Male } \\
(\mathrm{N}=277) \\
\%\end{array}$ & $\begin{array}{l}\text { Female } \\
(\mathrm{N}=697) \\
\%\end{array}$ & $\begin{array}{l}\text { Missing } \\
(\mathrm{N}=9) \\
\%\end{array}$ & $\begin{array}{l}\text { Both/ missing } \\
(\mathrm{N}=983) \\
\%\end{array}$ \\
\hline Show love, compassion, friendship, kindness & 52 & 68 & 56 & 63 \\
\hline $\begin{array}{l}\text { Provide hope, encouragement, advice \& } \\
\text { counsel for positive living }\end{array}$ & 42 & $49^{*}$ & 33 & 47 \\
\hline Show pity, sympathy, feel bad, sad or sorry & 44 & $40^{\text {ns }}$ & 33 & 41 \\
\hline Encourage to pray and/or trust in God & 15 & $25^{* *}$ & 22 & 22 \\
\hline $\begin{array}{l}\text { Encourage/remind to take ARVs and other } \\
\text { medicines always }\end{array}$ & 17 & $22^{\text {ns }}$ & 22 & 21 \\
\hline Discourage sexual activity/relationships & 18 & $15^{\mathrm{ns}}$ & 22 & 16 \\
\hline Encourage balanced diet & 5 & $21^{\star \prime}$ & 11 & 16 \\
\hline $\begin{array}{l}\text { Stop sharing sharp instruments and other } \\
\text { things }\end{array}$ & 14 & $16^{\text {ns }}$ & 0 & 15 \\
\hline $\begin{array}{l}\text { Encourage them to seek guidance and } \\
\text { counseling }\end{array}$ & 11 & $17^{*}$ & 0 & 15 \\
\hline $\begin{array}{l}\text { Encourage/support to seek medical } \\
\text { treatment including lab tests }\end{array}$ & 14 & $13^{\text {ns }}$ & 11 & 14 \\
\hline Assist with class or house work & 7 & $15^{\star \prime}$ & 0 & 13 \\
\hline Keep information confidential/secret & 8 & $11^{\mathrm{ns}}$ & 22 & 10 \\
\hline
\end{tabular}

Thirty one percent of the students reported actually knowing a fellow student in their school who was HIV positive. The reported actual reactions of students and teachers towards HIV positive students were, however, at variance with their reports of the hypothetical reactions. In most cases, the proportions reporting actual positive reactions towards HIV positive students were significantly lower than those reporting similar possible reactions (Table 4 ). In contrast, whereas only $2 \%$ reported that they would discriminate, isolate or stigmatize a fellow student who is HIV positive, nearly half $(47 \%)$ acknowledged that such students faced considerable 
discrimination, isolation and stigmatization (Table 4) not only from fellow students but teachers as well. This is supported by the following excerpts from the essays:

"Yes we have someone in our school who is HIV positive. I don't like to even touch her I think I can even get tempted to loving her and get infected. Other students don't want to talk to her..." (17-year old male).

"Yes I know someone in the school with AIDS ... some students isolate him some are friendly to him. But even some do not share with him, some beat him up, some do not want to be nearer to him." (20-year old male).

"Students tend to nickname such student for example there's a boy who was nicknamed poison 'woliru woofira'." (18-year old male).

"They don't associate with us and always make insulting comments about our stand saying that it was our will, this creates stigma and we find that leaving studies serves as the answer. They don't want our hugs or even things we eat, I think they should be sensitized that we don't want to be discriminated and AIDS does not catch by hugs and eats, we need their helps and encouragements. Even teachers should stop back biting us." (17-year old HIV positive male).

"Teachers have also resorted to nick naming him like for example 'Musuja' and rebuke him in public." (18-year old male).

Table 4: Distribution of most commonly cited possible and actual reactions by students who knew of a fellow student living with HIV in their school

\begin{tabular}{|c|c|c|}
\hline Reactions & $\begin{array}{r}\text { Possible reaction } \\
(\mathrm{N}=303) \\
\%\end{array}$ & $\begin{array}{r}\text { Actual reaction } \\
(\mathrm{N}=303) \\
\%\end{array}$ \\
\hline Show love, compassion, friendship, kindness & 61 & $56^{\text {ns }}$ \\
\hline $\begin{array}{l}\text { Provide hope, encouragement, advice \& counsel for positive } \\
\text { living }\end{array}$ & 47 & $13^{\mathrm{x}}$ \\
\hline Show pity, sympathy, feel bad, sad or sorry & 44 & 57 \\
\hline Discourage sexual activity/relationships & 32 & 5 \\
\hline Encourage to pray and/or trust in God & 23 & 6 \\
\hline Encourage/remind to take ARVs and other medicines always & 23 & 6 \\
\hline Encourage balanced diet & 17 & $<1$ \\
\hline Encourage/support to seek medical treatment including lab tests & 15 & 1 \\
\hline Stop sharing sharp instruments and other things & 13 & 3 \\
\hline Assist with class or house work & 12 & 4 \\
\hline Keep information confidential/secret & 12 & 4 \\
\hline Discriminate, isolate, stop friendship, stigmatize & 2 & 47 \\
\hline Tell others/gossip about it & 2 & 6 \\
\hline Encourage condom use & 4 & $1^{*}$ \\
\hline
\end{tabular}


With respect to what students could do to support in-school HIV positive children, most commonly cited responses include the avoidance of discrimination, isolation, stigmatization, physical and verbal abuse (72\%), showing love, compassion, care, kindness and friendship (56\%), giving encouragement, advice, peer guidance and counseling (56\%), and advising or encouraging the students to always take their medicines (25\%; Table 5). Besides the first two, other most commonly mentioned ways in which the school administration could support HIV positive students include providing or facilitating guidance and counseling (46\%), providing, advising or encouraging such students to have a balanced diet (25\%), and providing, advising or encouraging them to seek medical care $(22 \%)$.

Table 5: Distribution of commonly suggested ways in which students and the school administration can support HIV positive students

\begin{tabular}{|c|c|c|}
\hline Suggested ways of support & $\begin{array}{r}\text { Students } \\
(\mathrm{N}=983) \\
\%\end{array}$ & $\begin{array}{r}\text { Administration } \\
(\mathrm{N}=983) \\
\%\end{array}$ \\
\hline $\begin{array}{l}\text { Avoid discrimination, isolation, stigmatization, physical and verbal } \\
\text { abuse }\end{array}$ & 72 & $40^{*}$ \\
\hline Show love, compassion, care, kindness and friendship & 56 & 30 \\
\hline $\begin{array}{l}\text { Provide hope, encouragement, advice, guidance and counseling on } \\
\text { positive living, peer counseling }\end{array}$ & 56 & $1 "$ \\
\hline Advise and encourage to take medications always & 25 & 16 \\
\hline Assist them with class, house or any work/exempt from manual labor & 16 & 8 \\
\hline Advise and encourage to seek medical care & 14 & 22 \\
\hline Discourage them from sexual relationships & 13 & $12^{\pi}$ \\
\hline Pray for/encourage to pray and trust in God & 12 & $\mathrm{n} / \mathrm{a}$ \\
\hline $\begin{array}{l}\text { Encourage co-curricular activities, increased physical activity and } \\
\text { work hard }\end{array}$ & 10 & $8^{\text {ns }}$ \\
\hline Keep HIV status secrete, confidential and do not gossip about it & 8 & $111^{\circ}$ \\
\hline Advise, encourage and assist them to have balanced diet & 7 & 25 \\
\hline Start or join clubs for HIV/AIDS-related activities & 6 & $15^{n}$ \\
\hline Advise and encourage to seek or provide guidance and counseling & 6 & 46 \\
\hline $\begin{array}{l}\text { Facilitate/provide financial/material support, reduced/ no school fees } \\
\text { for HIV-positive }\end{array}$ & $\mathrm{n} / \mathrm{a}$ & 18 \\
\hline Create awareness of HIV-related issues/sex education & $\mathrm{n} / \mathrm{a}$ & 17 \\
\hline
\end{tabular}




\section{SCHOOL ATTENDANCE AND EDUCATIONAL ATTAINMENT}

One percent (5) of the respondents had never attended school. Of these, 4 were females, one was aged 16 years, two were aged 18 years, and the remaining two were 19 years old. Three of the respondents had never attended school because their parents died while they were still young, and the other 2 because of lack of school fees and materials. There was no significant difference between male and female respondents who had ever attended school (99.7\% vs. $99.1 \%$; $=0.33)$. In addition, $82 \%$ of those who had ever attended school were still in school by the time of the survey with no significant difference between male and female respondents ( $81 \%$ vs. $83 \% ; \mathrm{p}=0.63)$.

Nearly two-thirds (63\%) of those who had ever attended school but were not attending school at the time of the survey mentioned lack of school fees/materials as the main reason (Figure 1). Other reasons included illness $(16 \%)$, death of parent/guardian $(8 \%)$, poor performance $(4 \%)$, and completion $(2 \%)$. With the exception of poor performance, the differences between male and female respondents regarding the major reasons for not attending school are not statistically significant.

Figure 1: Distribution of study participants not currently attending school by the main reason for not doing so

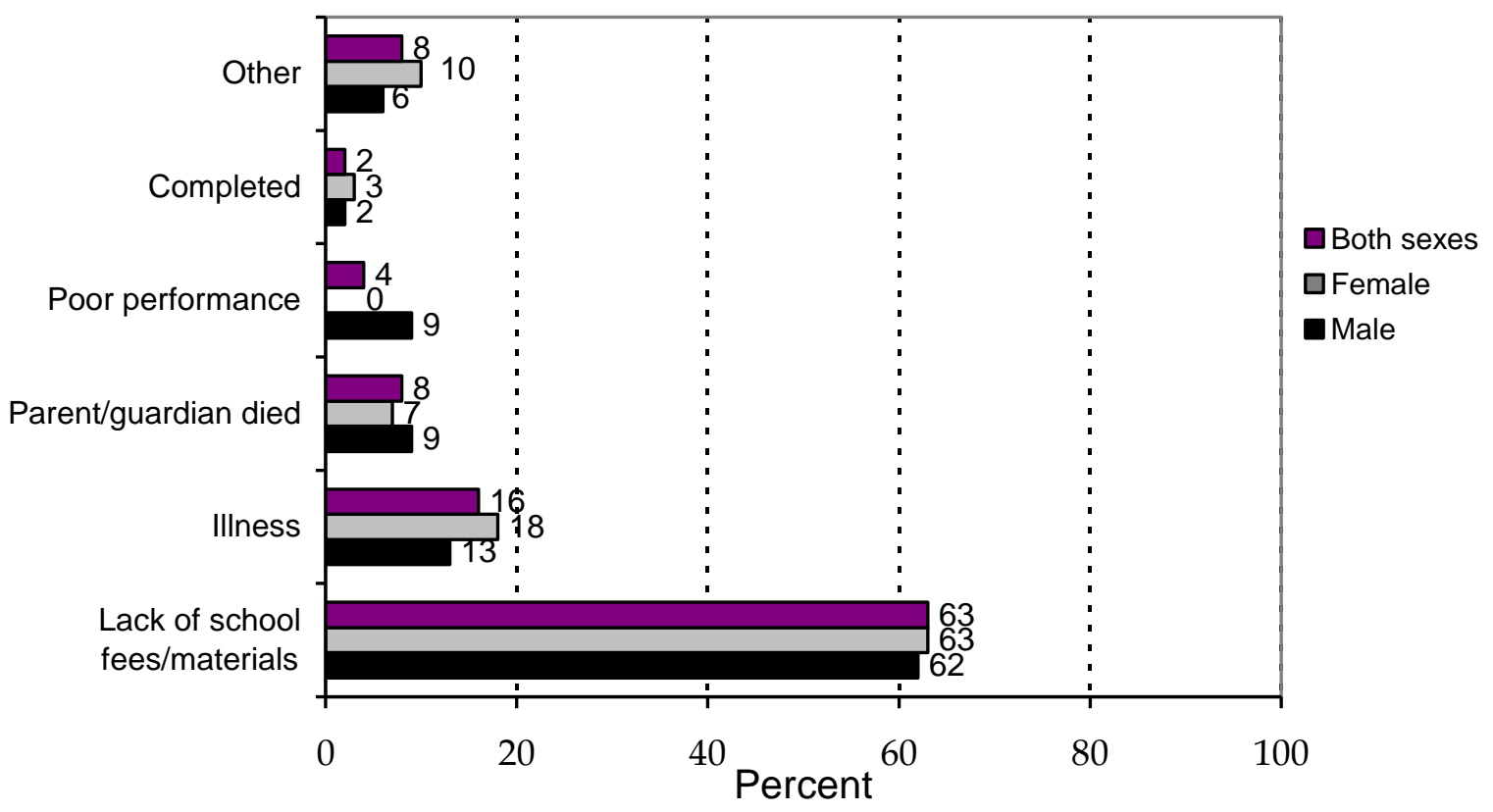

More than half (56\%) of those who had ever attended school had primary level education. However, it is worth noting that $40 \%$ of adolescents perinatally infected with HIV had attained secondary level education while $4 \%$ had gone beyond secondary schooling with no significant difference between male and female respondents (Table 6). With respect to absenteeism from school, close to half (46\%) of the adolescents currently attending school reported staying away from school the last school year while slightly more than half $(52 \%)$ missed attending school the last school term. Again, there was no significant difference in 
non-attendance of school between male and female respondents (Table 6). This has implications for their performance in school which might, in turn, influence mobility from one level to the next as suggested by the high proportion (55\%) reporting ever repeating a class.

The three most common reasons for missing school during the last school term were illness $(57 \%)$, lack of school fees or materials $(23 \%)$, and going for treatment/medicine $(12 \%)$. Class repetition, on the other hand, was mostly attributable to poor performance (35\%), illness $(35 \%)$, and lack of school fees or materials $(20 \%)$. Slightly less than a quarter of the respondents $(23 \%)$ currently attending school changed their learning institution during the last school year (Table 6) with the common reasons for the change being lack of or poor facilities/academic standards (32\%), high school fees (11\%), and long distance to the former school (10\%). Except for missing school because of going for treatment (18\% for males and $8 \%$ for females; $\mathrm{p}<0.01$ ), the other differences in the reasons for missing/changing school or repeating a class between male and female respondents are not statistically significant.

\begin{tabular}{|c|c|c|c|}
\hline Characteristics & Male (\%) & Female (\%) & Both (\%) \\
\hline Highest education level $^{\mathrm{a}}$ & $(\mathrm{N}=293)$ & $(\mathrm{N}=420)$ & $(\mathrm{N}=713)$ \\
\hline Primary & 59 & $53^{\text {ns }}$ & 56 \\
\hline Secondary 'O' Level & 35 & $34^{\mathrm{ns}}$ & 34 \\
\hline Secondary 'A' Level & 4 & $7^{\text {ns }}$ & 6 \\
\hline University/college/tertiary & 2 & $4^{\text {ns }}$ & 4 \\
\hline Missing & 0 & $1^{\text {ns }}$ & 1 \\
\hline Absenteeism $^{\mathrm{b}}$ & $(\mathrm{N}=238)$ & $(\mathrm{N}=347)$ & $(\mathrm{N}=585)$ \\
\hline Stayed away from school last school year & 47 & $44^{\text {ns }}$ & 46 \\
\hline Missed attending school last school term & 49 & $53^{\text {ns }}$ & 52 \\
\hline Ever repeated a class ${ }^{\mathrm{b}}$ & 56 & $55^{\mathrm{ns}}$ & 55 \\
\hline Frequency of repeating a class & $(\mathrm{N}=134)$ & $(\mathrm{N}=189)$ & $(\mathrm{N}=323)$ \\
\hline Once & 66 & $69^{\text {ns }}$ & 68 \\
\hline More than once & 34 & $30^{\text {ns }}$ & 32 \\
\hline Can't remember & 0 & $1^{\text {ns }}$ & 1 \\
\hline Changed school last school year $^{b}$ & 25 & $22^{\text {ns }}$ & 23 \\
\hline $\begin{array}{l}\text { Notes: }{ }^{a} \text { Among those who had ever attended sc } \\
\text { school; Differences between male and female pr } \\
\mathrm{p} p<0.01 ; \mathrm{p}<<0.05 ;{ }^{\text {ns }} \text { - not significant. }\end{array}$ & & urrently a & \\
\hline
\end{tabular}




\section{MOTIVATIONS FOR SCHOOLING}

Respondents who were still in school by the time of the survey were asked about how important schooling is to them, what motivates them to continue with schooling, and what they like and do not like about school. Nearly all respondents (95\%) recognized that schooling is very important to them with no significant difference between male and female participants ( $94 \%$ vs. $96 \%$; $=0.27$ ). Their major motivations to continue with schooling included future career prospects (69\%), encouragement from others (19\%), and the urge to gain new knowledge (12\%; Table 7). The experience of learning new things was the single most item the respondents liked about school (72\%), followed by the possibility of a brighter future (45\%), co-curricular activities (29\%), and making new friends $(28 \%)$. In contrast, punishment, bullying/ ridicule/rumors, unfriendly teachers/school nurse, and discrimination were some of the things the respondents did not like about school (Table 7).

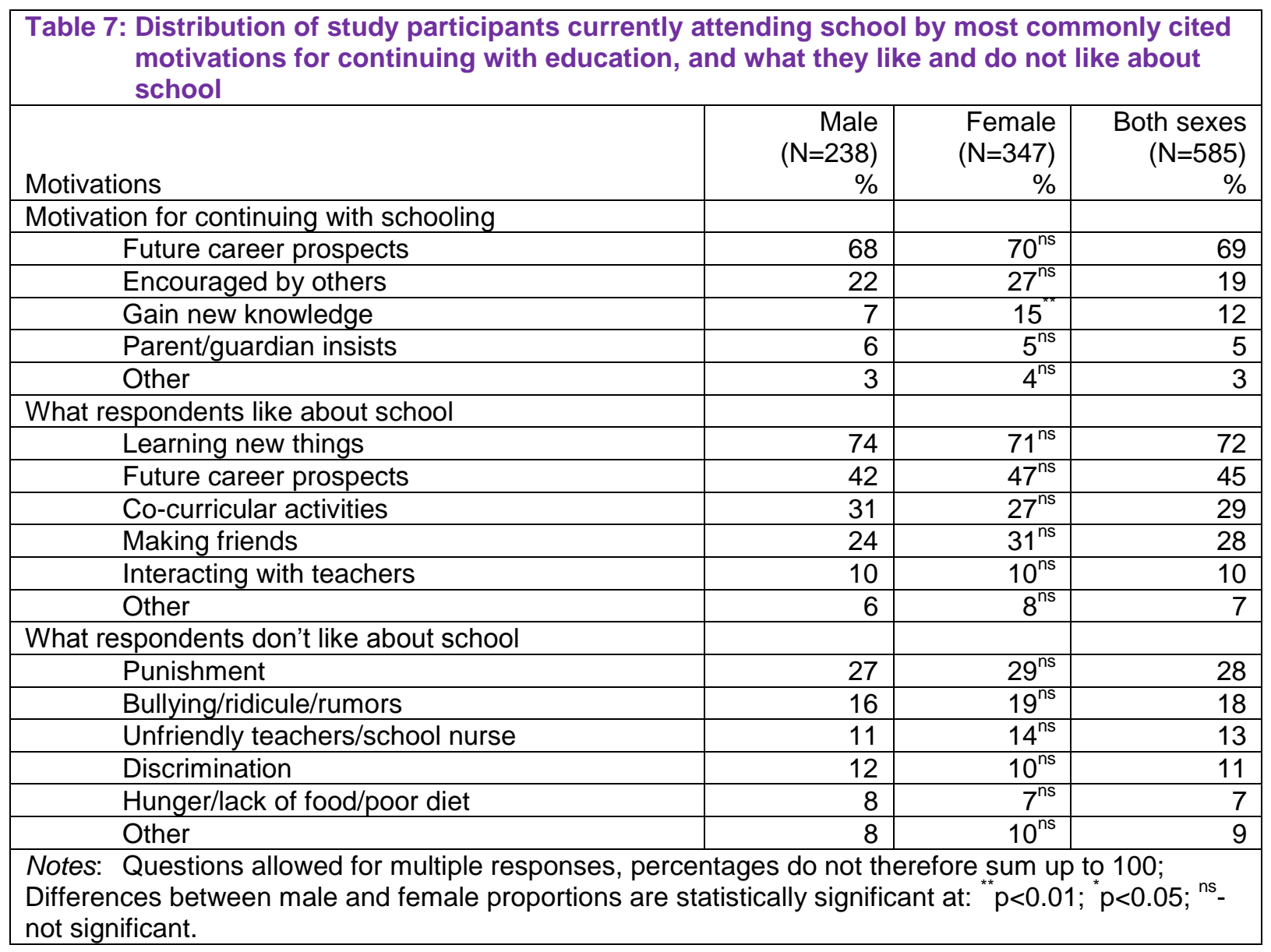




\section{DISCLOSURE OF HIV STATUS IN SCHOOL}

Respondents were asked about disclosure of their HIV status to school friends (for those who reported having such friends they can talk to about their lives), teachers and the school nurse. More than half (56\%) of those who had school friends had disclosed their HIV status to them while less than half $(47 \%)$ of the respondents currently attending school had disclosed their status to teachers (Figure 2).

Disclosure to teachers was either by self $(35 \%)$ or by parent/guardian $(12 \%)$. Also worth noting is the fact that although the school nurses are mandated to handle pupils' / students' health problems while at school, less than one-fifth (17\%) of the respondents had disclosed their status to them. There are no significant differences between male and female respondents with respect to disclosure of HIV status to others within the school environment.

Figure 2: Distribution of study participants currently attending school by whether they have

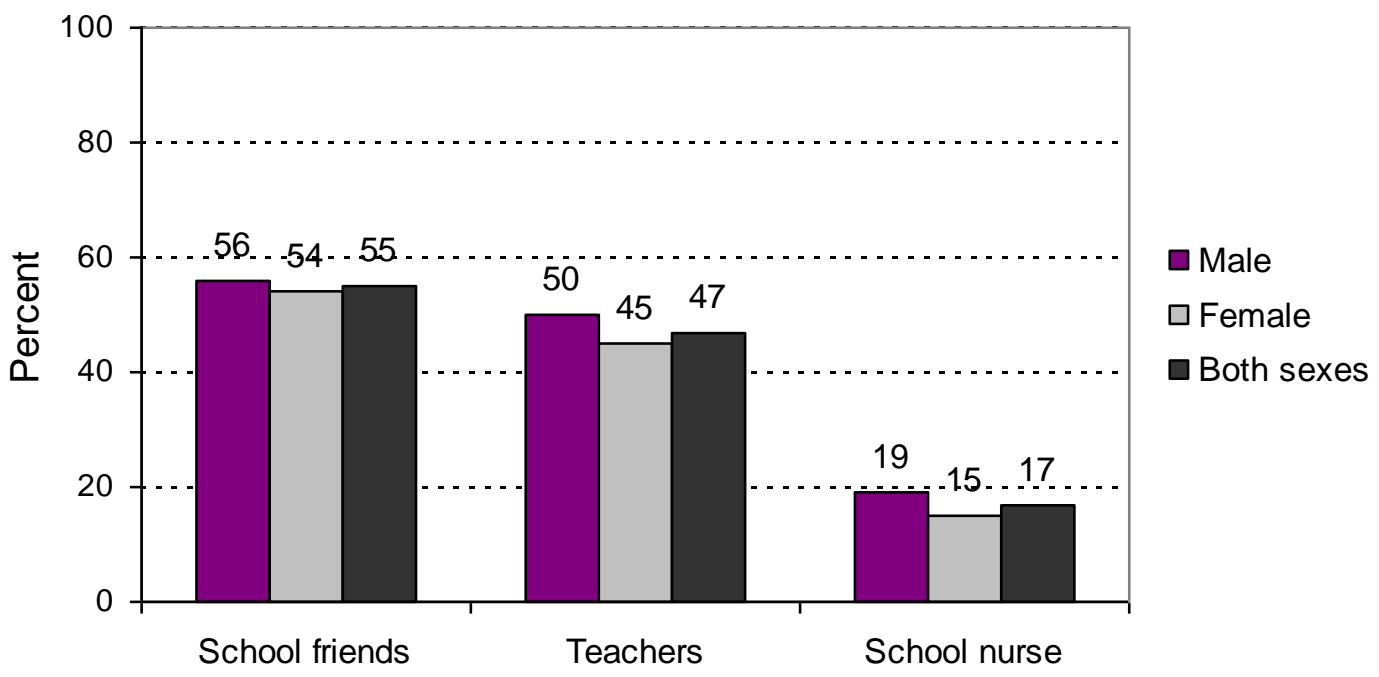

disclosed their HIV status to school friends, teachers or school nurse

Respondents who had disclosed their HIV status to teachers reported mostly doing so to the head teacher or the deputy $(57 \%)$, class teacher $(38 \%)$, or senior teacher $(12 \%)$ with only $4 \%$ reporting disclosing their status to guidance and counseling teacher. Again, there are no significant differences between male and female respondents regarding which teachers they disclosed their sero-status to.

Most respondents who had disclosed their HIV status to school friends reported that the latter showed compassion/sympathy $(65 \%)$, counseled them $(31 \%)$, or kept the information confidential (24\%; Table 8). Those who had disclosed their status to teachers reported that the latter mostly showed compassion/sympathy (70\%) or counseled the respondents (38\%). Besides these two, the school nurses also reacted by reminding, giving, or helping the respondent with medication. In most cases, the differences between male and female respondents with respect to the reactions of others are not statistically significant except for showing compassion/sympathy by the school nurse (Table 8). 
Respondents who had disclosed their HIV status to others in school were asked about the person who made the decision. Disclosure to school friends was largely an individual decision (78\%) with a significantly higher proportion of male than female respondents reporting that they made the decision themselves ( $85 \%$ vs. $73 \%$; $\mathrm{p}<0.05)$. The decision to disclose to teachers and the school nurse was, however, partly made by the respondent him/herself and partly by the parent/guardian with no significant difference between and female respondents. For instance, $40 \%$ of the respondents who had disclosed their HIV status to teachers reported that it was an individual decision and $49 \%$ reported that it was the parent/guardian who made the decision. The figures for who made the decision to disclose to the school nurse are $51 \%$ and $30 \%$ for individual and parent/guardian respectively. Health providers/counselors, other family members/relatives, teachers, and other friends played minimal roles in influencing the decision to disclose.

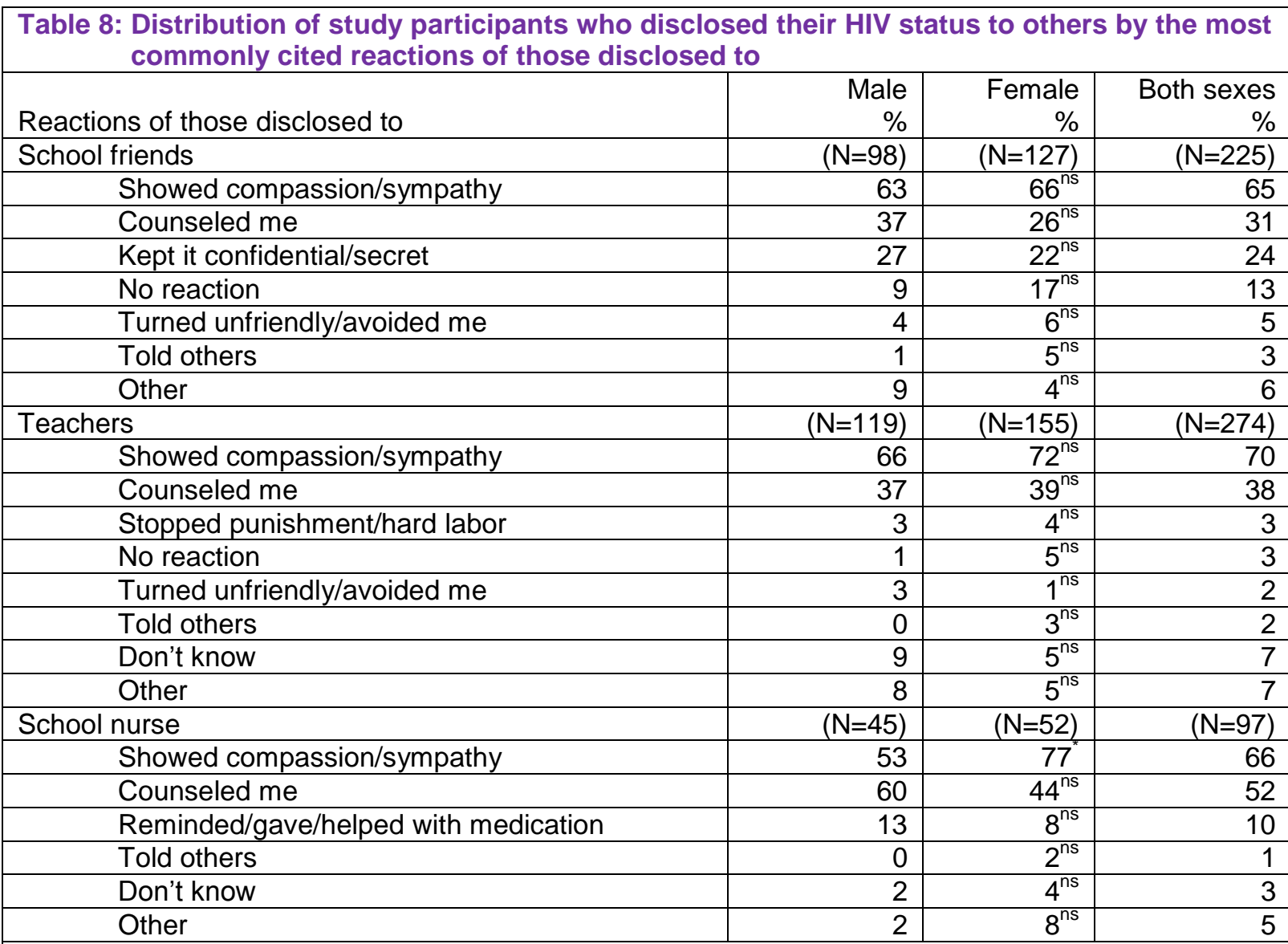

Notes: Questions allowed for multiple responses, percentages do not therefore sum up to 100;

Differences between male and female proportions are statistically significant at: ${ }^{* *} p<0.01 ; p<0.05$; ${ }^{\mathrm{ns}}$ not significant.

Among respondents who had not disclosed their HIV status to school friends, the main reasons for this were fear of discrimination/stigma (38\%), friends telling others $(34 \%)$, losing friends $(22 \%)$, or being ridiculed (17\%; Table 9$)$. Those who had not disclosed to teachers feared that the latter might tell others $(33 \%)$, discriminate/stigmatize them $(25 \%)$, or ridicule them $(13 \%)$. Close to one-fifth $(18 \%)$ did not have a reason for not disclosing to teachers. Similarly, almost one-quarter $(24 \%)$ of those who had not disclosed their HIV status to the school nurse had no 
reason for not doing so while others believed that the nurse could tell others $(19 \%)$, could not help even if they disclosed $(17 \%)$, or that the nurse could discriminate or stigmatize them (12\%; Table 9).

\begin{tabular}{|c|c|c|c|}
\hline Reasons for non-disclosure & $\begin{array}{r}\text { Male } \\
\%\end{array}$ & $\begin{array}{r}\text { Female } \\
\%\end{array}$ & $\begin{array}{r}\text { Both sexes } \\
\%\end{array}$ \\
\hline School friends & $(\mathrm{N}=77)$ & $(\mathrm{N}=107)$ & $(\mathrm{N}=184)$ \\
\hline Fears discrimination/stigma & 43 & $34^{\text {ns }}$ & 38 \\
\hline They might tell others & 27 & $39^{\text {ns }}$ & 34 \\
\hline Avoid losing friends & 16 & $27^{\text {ns }}$ & 22 \\
\hline Avoid being ridiculed & 17 & $17^{\text {ns }}$ & 17 \\
\hline There is no reason & 10 & $11^{\text {ns }}$ & 11 \\
\hline It is a personal matter & 13 & $9^{\text {ns }}$ & 11 \\
\hline They have not asked & 3 & $2^{\text {ns }}$ & 2 \\
\hline No need/they cannot help & 0 & $1^{\text {ns }}$ & 1 \\
\hline Don't know & 4 & $6^{\text {ns }}$ & 5 \\
\hline Other & 3 & $8^{\text {ns }}$ & 5 \\
\hline Teachers & $(\mathrm{N}=115)$ & $(\mathrm{N}=189)$ & $(\mathrm{N}=304)$ \\
\hline They might tell others & 34 & $33^{\text {ns }}$ & 33 \\
\hline Fears discrimination/stigma & 24 & $27^{\text {ns }}$ & 25 \\
\hline There is no reason & 18 & $19^{\text {ns }}$ & 18 \\
\hline Avoid being ridiculed & 13 & $13^{\text {ns }}$ & 13 \\
\hline It is a personal matter & 11 & $7^{\text {ns }}$ & 9 \\
\hline No need/they cannot help & 5 & $6^{\text {ns }}$ & 6 \\
\hline They have not asked & 4 & $6^{\text {ns }}$ & 6 \\
\hline Don't know & 6 & $4^{\text {ns }}$ & 5 \\
\hline School nurse & $(\mathrm{N}=61)$ & $(\mathrm{N}=139)$ & $(\mathrm{N}=200)$ \\
\hline There is no reason & 30 & $21^{\text {ns }}$ & 24 \\
\hline He/she might tell others & 10 & 22 & 19 \\
\hline No need/nurse cannot help & 18 & $16^{\text {ns }}$ & 17 \\
\hline Fears discrimination/stigma & 12 & $12^{\text {ns }}$ & 12 \\
\hline $\mathrm{He} / \mathrm{she}$ has not asked & 2 & $8^{\text {ns }}$ & 6 \\
\hline It is a personal matter & 5 & $4^{\text {ns }}$ & 5 \\
\hline Avoid being ridiculed & 0 & $6^{\text {ns }}$ & 4 \\
\hline Don't know & 7 & $7^{\text {ns }}$ & 7 \\
\hline
\end{tabular}




\section{EXPERIENCES OF ABUSE, STIGMA AND DISCRIMINATION}

Respondents who were still in school by the time of the survey were asked whether they have been teased or called nasty names at school because of their HIV status, whether they suspected rumors spreading about their sero status, and experiences of physical abuse at school. Sixteen percent reported being teased because of their HIV status with no significant difference between male and female respondents (Figure 3). A slightly higher proportion of male than female respondents reported being called nasty names because of their sero-status though the difference is not statistically significant. Close to a quarter (24\%) of the students suspected that rumors were spreading around in school about their status while $13 \%$ reported having been physically abused at school.

Figure 3: Distribution of study participants currently attending school by experiences of discrimination, stigma and physical abuse at school

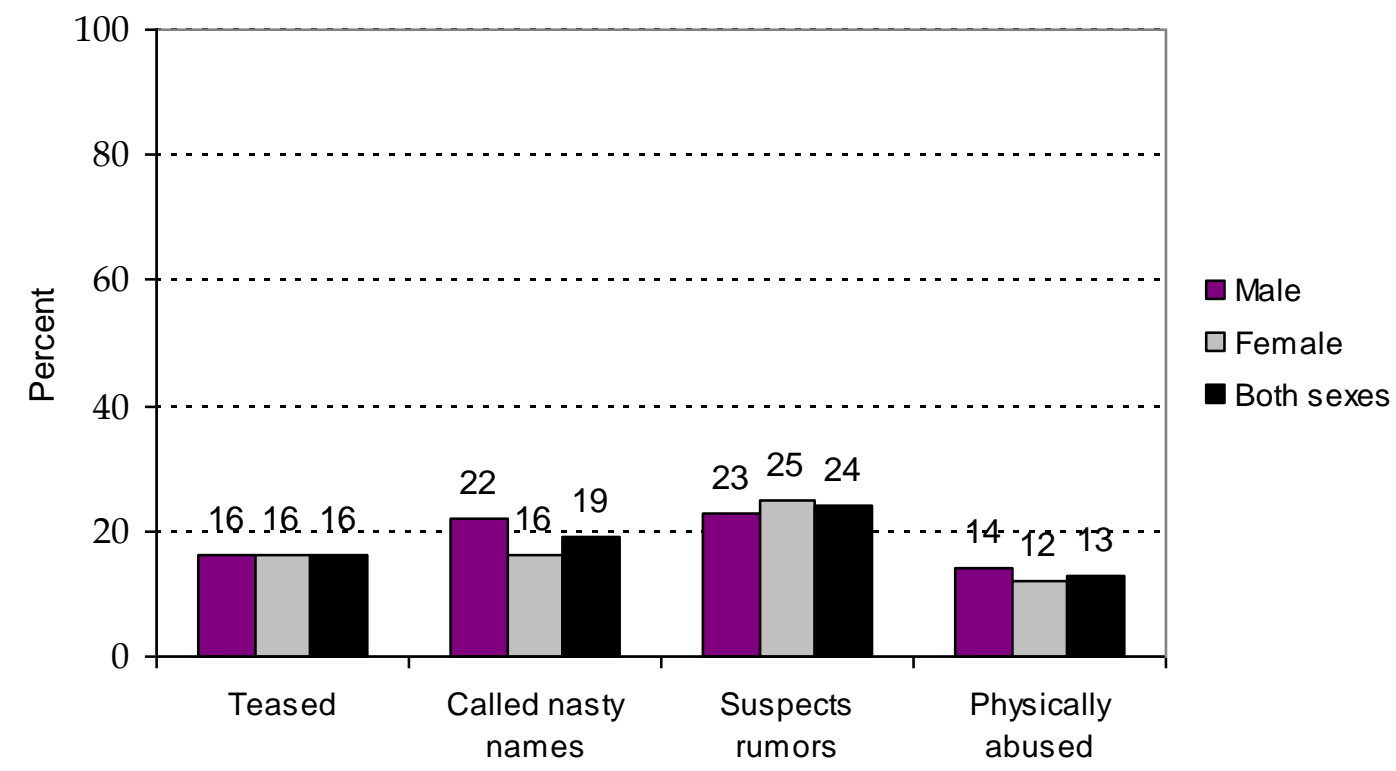

Of those who reported physical abuse, slightly more than two-thirds (68\%) reported discussing the problem with someone. A significantly higher proportion of female than male respondents reported discussing the problem with someone (79\% vs. 55\%; $\mathrm{p}<0.05)$. The persons with whom the respondents mostly discussed the problem of physical abuse were close friends (24\%), family members/relatives (22\%), head teachers $(20 \%)$, and senior teachers $(12 \%)$ with no significant difference between male and female respondents. 


\section{PSYCHOSOCIAL PROBLEMS AND SCHOOLING}

Respondents were further asked whether during the last school term they experienced feelings of negative attitude about going to school, worry, sadness/stress, pressure or anger that affected their concentration on school work. Figure 4 presents the percent distribution of respondents who experienced these psychosocial feelings. Less than one-fifth $(17 \%)$ had negative attitudes about going to school while close to one-third were worried or sad/stressed to the extent that this affected their concentration on school work (30\% and 32\% respectively). A significantly higher proportion of female than male respondents reported having negative about going to school or feeling sad/stressed during the last school term.

Figure 4: Distribution of study participants currently attending school by experiences of psychosocial problems during the last school term

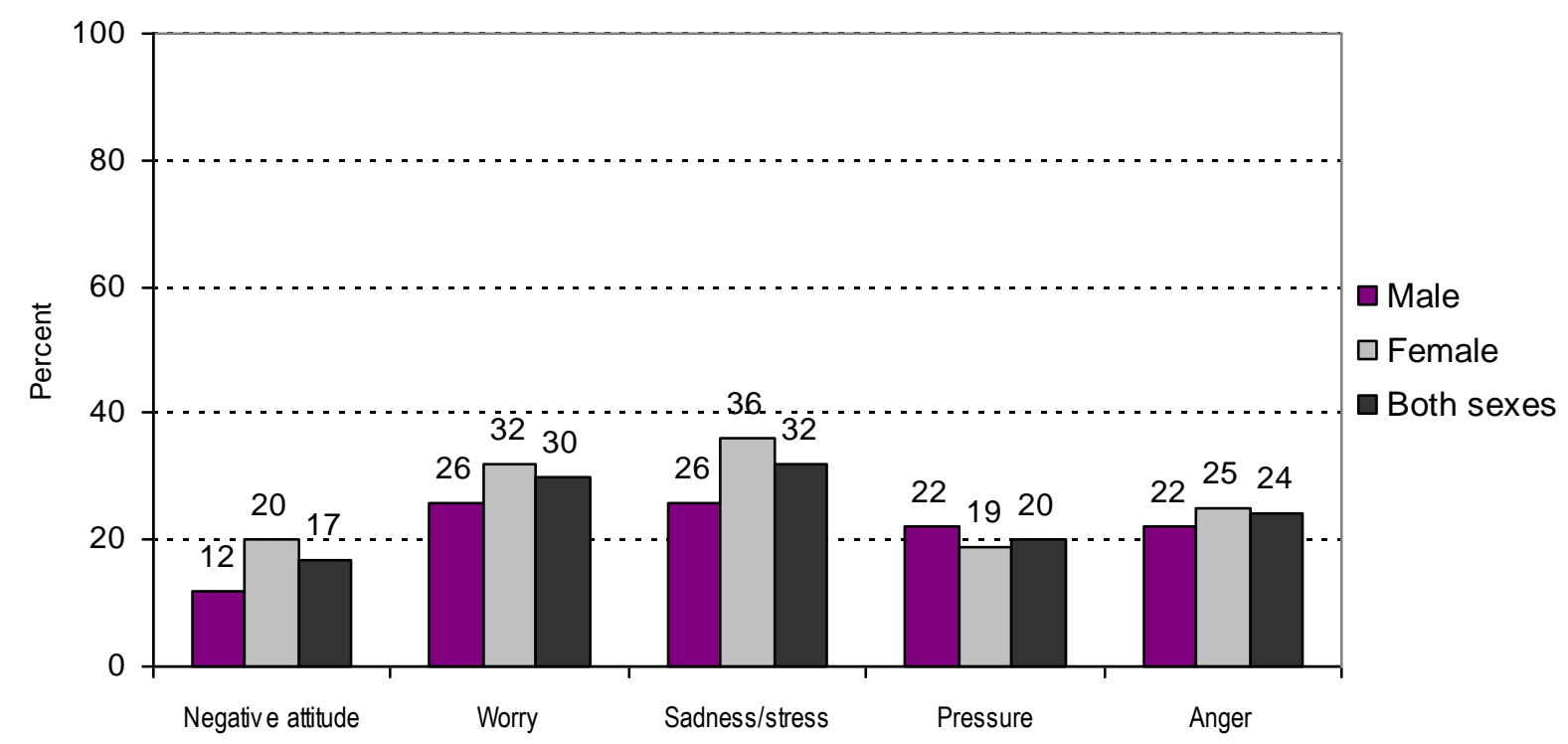

The most common sources of worry were lack of school fees/resources (18\%) and poor health status (17\%; Table 10). A significantly higher proportion of male than female respondents reported being worried about their poor health status $(26 \% \mathrm{vs}$. $11 \% ; \mathrm{p}<0.05)$. The death or illness of a family member/relative, the deteriorating health status, knowing about HIV status and the consequent fear of death as well as lack of school fees resources were the major reasons for sadness/stress with no significant difference between male and female respondents (Table 10). Feelings of pressure, on the other hand, mostly resulted from too much or difficult school work $(15 \%)$, lack of school fees/resources $(15 \%)$, and poor or deteriorating health status $(14 \%)$, again with no significant difference between male and female respondents. It is also worth noting that most respondents who experienced feelings of anger mentioned students or teachers as the major source $(43 \%)$, followed by parent/guardian (14\%) and other persons (11\%). A significantly higher proportion of male than female respondents mentioned students/teachers (53\% vs. 36\%; $\mathrm{p}<0.05)$. 


\begin{tabular}{|c|c|c|c|}
\hline Main reasons & $\begin{array}{r}\text { Male } \\
\%\end{array}$ & $\begin{array}{r}\text { Female } \\
\%\end{array}$ & $\begin{array}{r}\text { Both sexes } \\
\%\end{array}$ \\
\hline Worry & $(\mathrm{N}=62)$ & $(\mathrm{N}=112)$ & $(\mathrm{N}=174)$ \\
\hline Lack of school fees/resources & 15 & $20^{\text {ns }}$ & 18 \\
\hline Poor health status & 26 & 11 & 16 \\
\hline Learning about sero status & 11 & $7^{\mathrm{ns}}$ & 9 \\
\hline Death/illness of a family member/relative & 8 & $8^{\text {ns }}$ & 8 \\
\hline Punishment by teachers & 8 & $5^{\text {ns }}$ & 6 \\
\hline Sadness/stress & $(\mathrm{N}=61)$ & $(\mathrm{N}=123)$ & $(\mathrm{N}=184)$ \\
\hline Death/illness of a family member/relative & 23 & $21^{\text {ns }}$ & 22 \\
\hline Deteriorating health status & 20 & $28^{\text {ns }}$ & 19 \\
\hline Knowing HIV status/fear of death & 10 & $15^{\mathrm{ns}}$ & 14 \\
\hline Lack of school fees/resources & 5 & $14^{\mathrm{ns}}$ & 11 \\
\hline Discrimination/stigma at school & 5 & $8^{\text {ns }}$ & 7 \\
\hline Pressure from & $(\mathrm{N}=52)$ & $(\mathrm{N}=66)$ & $(\mathrm{N}=118)$ \\
\hline Too much/difficult school work & 17 & $14^{\text {ns }}$ & 15 \\
\hline Lack of school fees/resources & 14 & $17^{\mathrm{ns}}$ & 15 \\
\hline III/poor/deteriorating health status & 21 & $9^{\text {ns }}$ & 14 \\
\hline Death/illness of a family member/relative & 8 & $9^{\text {ns }}$ & 9 \\
\hline Unfriendly teachers/students & 6 & $9^{\text {ns }}$ & 8 \\
\hline Angered by & $(\mathrm{N}=53)$ & $(\mathrm{N}=88)$ & $(\mathrm{N}=141)$ \\
\hline Students/teachers & 53 & 36 & 43 \\
\hline Parent/guardian & 8 & $17^{\mathrm{ns}}$ & 14 \\
\hline Other persons & 8 & $13^{\mathrm{ns}}$ & 11 \\
\hline Learning about HIV status & 4 & $5^{\mathrm{ns}}$ & 4 \\
\hline Lack of school fees/resources & 2 & $6^{\text {ns }}$ & 4 \\
\hline
\end{tabular}

Most of those who had these feelings reported experiencing them a few times with no significant difference between male and female respondents (Figure 5).

Nonetheless, more than one-in-three (36\%), one-third (33\%), and an almost similar proportion $(30 \%)$ of the respondents reported being worried, feeling sad/stressed or pressure respectively always or most of the time. 
Figure 5: Distribution of study participants who experienced psychosocial problems during the last school term by the frequency of the feelings

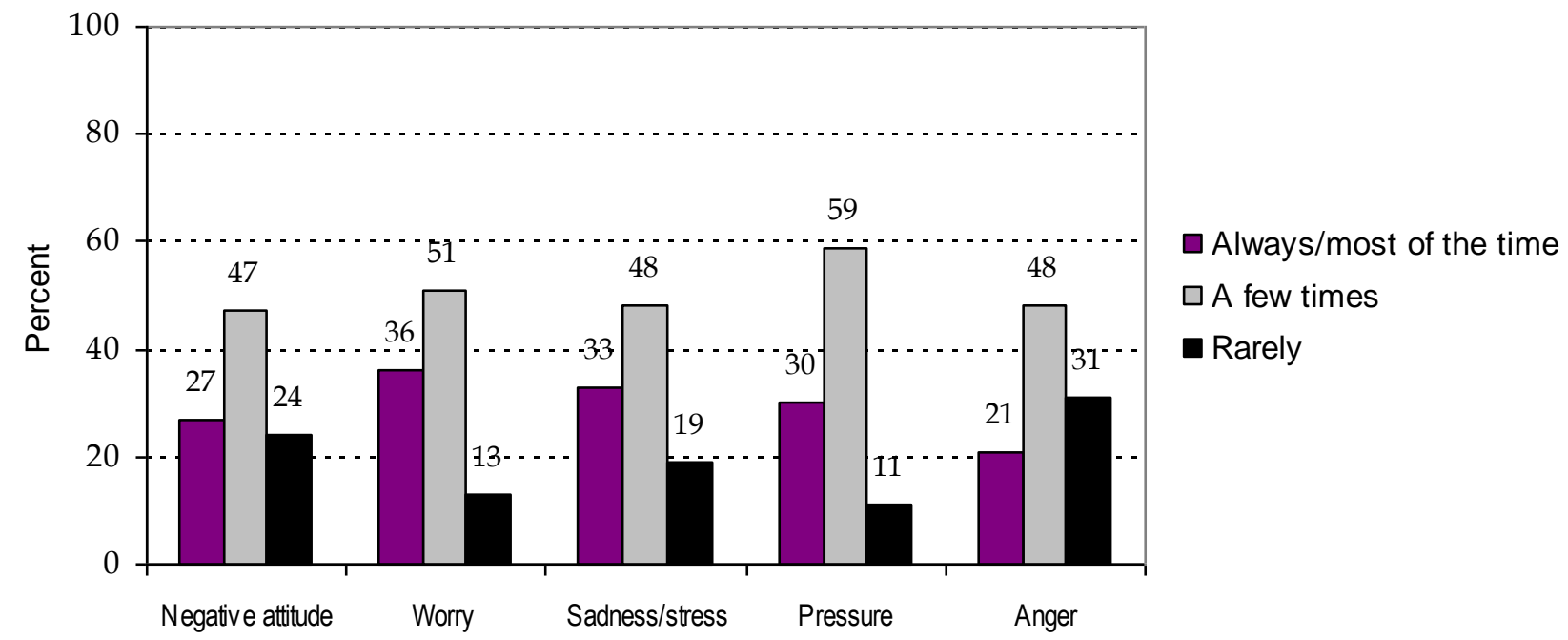

With respect to whether the feelings affected school attendance, nearly one-half $(47 \%)$ reported that having negative attitude about going to school made them stay away from school (Figure 6). Slightly more than one-in-three (35\%) and close to onethird $(32 \%)$ indicated that feelings of pressure and sadness/stress kept them away from school. There were no significant differences in the proportions of male and female respondents who stayed away from school because of the psychosocial problems.

Figure 6: Distribution of study participants who experienced psychosocial problems during the last school term by whether this affected school attendance

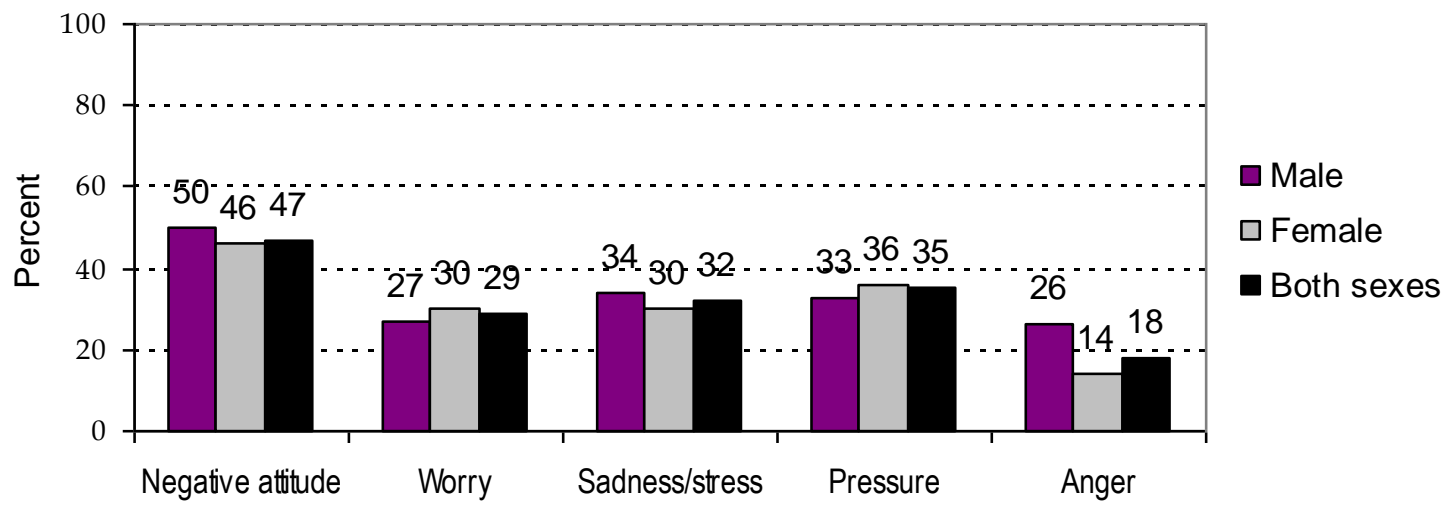

In all cases, more than half of those who stayed away from school because of psychosocial problems did so a few times (Figure 7). However, nearly one-in-four of the respondents reported staying away from school always or most of the time because of worry $(24 \%)$ or pressure $(22 \%)$. Again, there were no significant differences between male and female respondents in the frequency of nonattendance of school because of the psychosocial problems. 
Figure 7: Distribution of study participants who stayed away from school because of psychosocial problems by the frequency of non-attendance

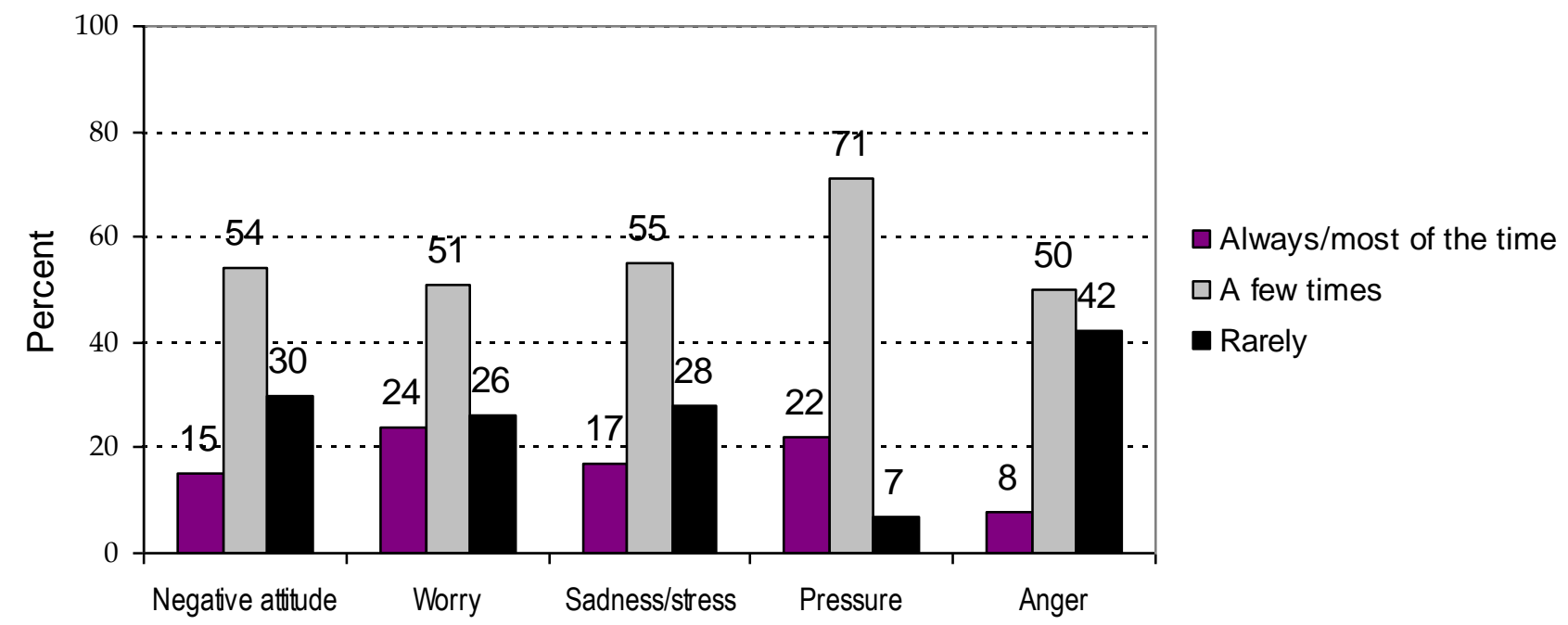

\section{SUPPORT GROUPS AND SERVICES IN SCHOOLS}

Only a small fraction (16\%) of the respondents currently attending school reported having support groups or clubs for HIV positive young people in their learning institutions (Table 11). Of those whose institutions had such groups/clubs, the majority $(73 \%)$ were members. The kind of support provided by the groups/clubs mainly included taking medicine (38\%), counseling or moral support $(29 \%)$, basic needs $(27 \%)$, and life skills training (18\%). Nearly all respondents (94\%) who were members of these groups/clubs expressed satisfaction with the kind of support they received with no significant difference between male and female respondents. In addition, about three-in-four (78\%) of the respondents currently attending school felt that it is useful to have such support groups/clubs in schools.

Similar to the availability of support groups/clubs in schools, only a small fraction $(15 \%)$ of the respondents currently attending school reported receiving any kind of support from the learning institutions (Table 11). A significantly higher proportion of male than female respondents reported receiving any support from school $(19 \%$ vs. $13 \%$; p < 0.05$)$. The kind of support provided by schools mostly included basic needs $(33 \%)$, treatment or taking medicine $(20 \%)$, fee payment or provision of stationery (19\%), and counseling or moral support (16\%). Again, nearly all (92\%) those who received support from schools expressed satisfaction with it. Head teachers and others (sponsoring individuals and non-governmental organizations) provided much of the support received by the pupils/students (Table 11). 


\begin{tabular}{|c|c|c|c|}
\hline & \multicolumn{3}{|c|}{$\begin{array}{l}\text { Support groups/clubs for HIV positive } \\
\text { young people }\end{array}$} \\
\hline Support groups/services & $\begin{array}{r}\text { Male } \\
\%\end{array}$ & $\begin{array}{r}\text { Female } \\
\%\end{array}$ & $\begin{array}{r}\text { Both sexes } \\
\%\end{array}$ \\
\hline Have support groups/clubs in school ${ }^{\mathrm{a}}$ & 18 & $14^{\text {ns }}$ & 16 \\
\hline Is a member of such groups/clubs ${ }^{b}$ & 74 & $71^{\text {ns }}$ & 73 \\
\hline Kind of support received from the groups/clubs ${ }^{\mathrm{C}}$ & $(\mathrm{N}=32)$ & $(\mathrm{N}=34)$ & $(\mathrm{N}=66)$ \\
\hline Taking medicine & 47 & $29^{\text {ns }}$ & 38 \\
\hline Counseling/moral support & 19 & $38^{\text {ns }}$ & 29 \\
\hline Basic needs & 28 & $27^{\mathrm{ns}}$ & 27 \\
\hline Life skills training & 19 & $18^{\text {ns }}$ & 18 \\
\hline Other & 22 & $18^{\text {ns }}$ & 20 \\
\hline Satisfied with support received from groups/clubs & 97 & $91^{\mathrm{ns}}$ & 94 \\
\hline \multirow[t]{2}{*}{ Useful to have support groups in schools for $\mathrm{HIV}_{+}{ }^{\mathrm{a}}$} & 76 & $80^{\mathrm{ns}}$ & 78 \\
\hline & \multicolumn{3}{|c|}{ Support received from school } \\
\hline Receives any kind of support from school $^{\mathrm{a}}$ & 19 & 13 & 15 \\
\hline Kind of support received from school ${ }^{\mathrm{C}}$ & $(\mathrm{N}=44)$ & $(\mathrm{N}=45)$ & $(\mathrm{N}=89)$ \\
\hline Basic needs & 39 & $27^{\text {ns }}$ & 33 \\
\hline Treatment/taking medicine & 21 & $20^{\text {ns }}$ & 20 \\
\hline Fee payment/stationery & 18 & $20^{\text {ns }}$ & 19 \\
\hline Counseling/moral support & 18 & $13^{\text {ns }}$ & 16 \\
\hline Life skills training & 2 & $4^{\text {ns }}$ & 3 \\
\hline Other & 11 & $11^{\text {ns }}$ & 11 \\
\hline Person providing support received at school ${ }^{C}$ & $(\mathrm{~N}=44)$ & $(\mathrm{N}=45)$ & $(\mathrm{N}=89)$ \\
\hline Head teacher & 50 & $38^{\text {ns }}$ & 44 \\
\hline School friends & 7 & $14^{\mathrm{ns}}$ & 10 \\
\hline Other teachers & 5 & $9^{\text {ns }}$ & 7 \\
\hline Guidance/counseling teacher & 5 & $4^{\text {ns }}$ & 5 \\
\hline Class teacher & 0 & $7^{\text {ns }}$ & 3 \\
\hline Senior teacher & 5 & $0^{\text {ns }}$ & 2 \\
\hline Other & 39 & $31^{\mathrm{ns}}$ & 35 \\
\hline & 96 & $89^{\text {ns }}$ & 92 \\
\hline \multicolumn{4}{|c|}{$\begin{array}{l}\text { Notes: }{ }^{a} \text { Among participants currently attending school ( } 238 \text { male and } 347 \text { female respondents); } \\
\text { bemong those who reported having support groups/clubs for HIV positive young people in school ( } 43 \\
\text { male and } 48 \text { female respondents); }{ }^{\circ} \text { Questions allowed for multiple responses, percentages do not } \\
\text { therefore sum up to } 100 ; \text {; Differences between male and female proportions are statistically significant } \\
\text { at: }{ }^{* *} p<0.01 ; ;^{*} p<0.05 ;{ }^{n s} \text { - not significant. }\end{array}$} \\
\hline
\end{tabular}




\section{SUMMARY OF FINDINGS}

Consistent with a previous study that examined the sexual and reproductive health needs of adolescents perinatally infected with HIV in Uganda (Birungi et al. 2008), the findings of this study show that these adolescents aspire for better lives in future just like their counterparts who are HIV-negative. They recognize the importance of schooling towards achieving that better life and the majority reported this as a motivation for continuing with education. However, in-school HIV positive young people have a number of special needs that are not adequately addressed by the education sector in the country. These include:

- Lack of adequate material support for schooling: Both school officials and the adolescents perinatally infected with HIV recognized lack of adequate material support (fees and learning materials) for adolescents living with HIV in schools. This is largely occasioned by the fact that most of the adolescents are orphans having lost one or both parents. In-depth interviews with school officials reveal that support from guardians is not always adequate as some of them believe that the children might not live long or simply because of poverty. It is one of the main reasons for missing school or repeating classes, as well as for experiencing psychosocial problems which, in turn, affect school attendance and performance.

- Lack of proper mechanisms for health care in schools: Illness and having to seek treatment from elsewhere are major factors in missing or not currently attending school among adolescents perinatally infected with HIV. They are also some of the most commonly cited reasons for experiencing psychosocial problems. Indepth interviews with school officials further show that HIV positive young people in boarding institutions face additional challenges such as poor diet, adherence to ART, and taking cold showers. These have implications for academic performance. However, schools lack formally established mechanisms for meeting these needs. Moreover, sick-bays-- where they exist in schools-- are ill-equipped while the school nurses are inadequately trained to handle the health needs of HIV positive young people.

- Lack of training in HIV care and support for caregivers: In-depth interviews with school officials showed that most of those who provide some kind of support at school to HIV positive adolescents lack appropriate training in HIV care and support. These include the school nurses, guidance and counseling teachers, and senior teachers. Adolescents perinatally infected with HIV who received some kind of support from schools reported receiving the same from head teachers as well, who might also not have adequate training in HIV care and support.

- Non-disclosure of HIV status in school: More than half of the adolescents had not disclosed their HIV status to teachers and four-in-five had not disclosed to the school nurse. In-depth interviews with school officials reveal that nondisclosure of HIV status is a major impediment to providing appropriate and timely support to in-school HIV positive adolescents. The fear of stigma or 
discrimination, losing friends, being ridiculed, or of those disclosed to telling others were some of the major reasons for non-disclosure of HIV status at school. In-depth interviews with school officials further showed that parents/guardians feared that their children might not be admitted in school if they disclosed their (children's) HIV status. It is, however, worth noting that those who had disclosed their sero-status to others mostly reported being shown compassion/sympathy, counseled, or being helped with medication, which suggests that some of the fears about disclosure might be unfounded.

- Lack of support groups/clubs or services in school: Only a small fraction of the adolescents reported having support groups/clubs for HIV positive young people in their learning institutions or receiving any kind of support from school. Whereas it can be argued that the existence of support groups/clubs or services in schools specifically for HIV positive young people can reinforce stigma and discrimination, the findings of this study show the contrary. Rather, nearly all those who received some kind of support from the groups/clubs or schools-where these exist-- were satisfied with it. Furthermore, the majority of those currently attending school supported the need for having such groups/clubs in schools. The establishment of such groups/clubs was also one of the ways in which the school administration could support in-school HIV positive young people that the students identified in the essays.

- Discrimination, stigma and physical abuse in schools: The fact that the existence of support groups/clubs or services for in-school HIV positive young people does not reinforce stigma or discrimination does not imply that these problems do not exist. In fact, nearly one-in-five of the perinatally infected adolescents currently attending school reported being teased or called nasty names at school because of their HIV status, and one-four suspected rumors spreading in school about their sero-status. In addition, in-depth interviews with school officials and student essays show that stigma and discrimination of in-school HIV positive young people-- either by others or self-imposed-- is still a problem. 


\section{Programmatic IMPLICATIONS}

The above findings have a number of programmatic implications, which include:

- School-based programs to assist orphans and other vulnerable children: The study shows that orphans and other vulnerable children, including those living with HIV lack the relevant learning materials and other basic needs (such as lack of proper diet) that affect school attendance, and which could affect their academic performance as well. The Ministry of Education and Sports, in collaboration with other relevant ministries, therefore needs to come up with a school-based program that caters for the special needs of not only these children but also all orphans and other vulnerable children so that they do not miss attending school for lack of essentials.

- Strengthen the school-based health care program: The Ministry of Education and Sports needs to collaborate with the Ministry of Health to strengthen the schoolbased health care program. The program should include treatment, care and support for HIV positive pupils/students, encouraging in-school young people to undergo testing and counseling for HIV, and equipping the sick bays-- where these exist-- with essential medicines such as antibiotics and anti-malarial drugs. A common theme from the in-depth interviews with school officials and the student essays is to enhance the capacity of schools to either provide these services or have in place proper mechanisms for referring pupils/students in need of the services to the relevant facilities. Having counselors from the treatment centers visit schools to provide guidance and counseling is another way of strengthening the health care program in schools that was identified by school officials and students alike. The other strategy for strengthening the health care program in schools is to replicate the youth-friendly health services all over the country so as increase the chances of appropriate referral to these facilities by the schools.

- Offer caregivers at school training in HIV care and support: The fact that school nurses and teachers who provide some kind of support to in-school HIV positive young people lack the relevant training suggests the need for the Ministry of Education and Sports to offer pre- or in-service training-- as appropriate-- in counseling, care and support to these caregivers. For pre-service training, these themes need to be incorporated in the curriculum. In-service training needs to focus on enhancing the capacity of school nurses, teachers, matrons and all those that directly interact with pupils/students to effectively manage and support those in need of HIV and AIDS-related services as a strategy for strengthening the health care program in schools as well.

- Encourage the formation of support groups or clubs for HIV positive young people in schools: The study finds that nearly all respondents with support groups/clubs for HIV positive young people in their schools and are members are satisfied with the kind of support they receive although only a very small fraction reported having such groups/clubs in their learning institutions. The 
Ministry of Education and Sports therefore needs to come up with a policy encouraging schools to have such groups/clubs. The fact that most of those who are members are satisfied with the support they receive suggests that the groups/clubs could be a way of fighting rather than reinforcing stigma and discrimination. The clubs could be expanded to incorporate all pupils/students irrespective of their HIV status but with the objective of supporting those who are HIV positive as well as fighting stigma and discrimination through the use of innovative ways such as child-to-child education and communication.

- Measures to discourage stigma and discrimination: The need for measures that discourage stigma and discrimination of in-school HIV positive students was a recurring theme in the in-depth interviews with school officials and the student essays. This can be achieved, for instance, through programs aimed at sensitizing school officials and students on the consequences of discrimination and stigmatization on those who are exposed to them. The Ministry of Education and Sports therefore needs to collaborate with school officials to formulate a policy that outlines measures aimed at discouraging stigma and discrimination of inschool HIV positive young people. Such measures include programs aimed at educating school officials and teachers about HIV/AIDS, as well as advocacy to have school management allocate resources for anti-AIDS campaigns within the school budget. This could, in turn, increase the propensity to disclose one's serostatus, and ensure appropriate and timely response to the needs of HIV positive students by the school officials. In addition, having HIV/ AIDS counselors in schools could help reduce self-imposed stigma. 


\section{REFERENCES}

Birungi, Harriet, John Frank Mugisha, Juliana Nyombi, Francis Obare, Humphres Evelia, and Hannington Nyinkavu. 2008. "Sexual and reproductive health needs of adolescents perinatally infected with HIV in Uganda." FRONTIERS Final Report. Washington, DC: Population Council.

Kelly, M.J. 2003. “The Development of HIV/AIDS Policies in the Education Sector in Africa." DPMN Bulletin: Volume X, Number 1, January 2003.

Ministry of Education and Sports. 2004. Republic of Uganda: Education Sector Policy on HIV/AIDS. Kampala: Ministry of Education and Sports. 
One Dag Hammarskjold Plaza, New York I Dag Hammarskjold Plaza, 9th Floor New York NY USA 10017

Tel: + I 2 I2 3390500

Fax: + I 2127556052
General Accident House Ralph Bunche Road Nairobi

Kenya

Tel: +254-27 | 3-480

Fax: +254-27।3-479

\section{$(P$ Population Council

